Issued by Sandia National Laboratories, operated for the United States Department of Energy by Sandia Corporation.

NOTICE: This report was prepared as an account of work sponsored by an agency of the United States Government. Neither the United States Government, nor any agency thereof, nor any of their employees, nor any of their contractors, subcontractors, or their employees, make any warranty, express or implied, or assume any legal liability or responsibility for the accuracy, completeness, or usefulness of any information, apparatus, product, or process disclosed, or represent that its use would not infringe privately owned rights. Reference herein to any specific commercial product, process, or service by trade name, trademark, manufacturer, or otherwise, does not necessarily constitute or imply its endorsement, recommendation, or favoring by the United States Government, any agency thereof, or any of their contractors or subcontractors. The views and opinions expressed herein do not necessarily state or reflect those of the United States Government, any agency thereof, or any of their contractors.

Printed in the United States of America. This report has been reproduced directly from the best available copy.

Available to DOE and DOE contractors from

Office of Scientific and Technical Information

P.O. Box 62

Oak Ridge, TN 37831

Prices available from (703) 605-6000

Web site: http://www.ntis.gov/ordering.htm

Available to the public from

National Technical Information Service

U.S. Department of Commerce

5285 Port Royal Rd

Springfield, VA 22161

NTIS price codes

Printed copy: A03

Microfiche copy: A01

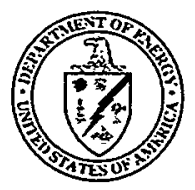




\section{DISCLAIMER}

Portions of this document may be illegible in electronic image products. Images are produced from the best available original document. 
SAND 99-3038

Unlimited Release

Printed December 1999

\title{
Freeforming Of Ceramics and Composites From Colloidal Slurries
}

\author{
J. Cesarano III, H. B. Denham, J. N. Stuecker \\ Materials and Process Sciences Center \\ T. A. Baer \\ Engineering Sciences Center \\ M. L. Griffith \\ Manufacturing Technology Center \\ Sandia National Laboratories \\ P.O. Box 5800 \\ Albuquerque, NM 87185-1349
}

\begin{abstract}
This report is a summary of the work completed for an LDRD project. The objective of the project was to develop a solid freeform fabrication technique for ceramics and composites from fine particle slurries. The work was successful and resulted in the demonstration of a manufacturing technique called robocasting. Some ceramic components may now be fabricated without the use of molds or tooling by dispensing colloidal suspensions through an orifice and stacking two-dimensional layers into three-dimensional shapes. Any conceivable two-dimensional pattern may be "written" layer by layer into a three-dimensional shape. Development of the robocasting technique required the materials expertise for fabrication and rheological control of very highly concentrated fine particle slurries, and development of robotics for process control and optimization. Several ceramic materials have been manufactured and characterized. Development of techniques for robocasting multiple materials simultaneously have also been developed to build parts with unique structures or graded compositions.
\end{abstract}




\section{SUMMARY}

This LDRD project entitled "Freeforming of Ceramics and Composites From Colloidal Slurries" resulted in the development of a new manufacturing technique called robocasting. Robocasting is a solid freeform fabrication technique for fine particles that uses computer controlled layer-wise extrusion of colloidal suspensions. Complicated and unique components may be manufactured without the use of molds or containers. The process is essentially binderless (with less than $1 \%$ organics) and parts can be fabricated, dried, and completely sintered in less than 24 hours. The process does not require waxes, thermosetting polymers, or polymerization reactions to build parts. Instead, robocasting relies upon highly concentrated aqueous suspensions that can rapidly transition from a pseudoplastic rheology to a dilatant solid-like state, upon minimal drying. Particle sizes are typically 0.5 to $5 \mu \mathrm{m}$ and the suspension solids loadings range between 50 and 61 volume percent solids, depending on the particle size distribution. The colloidal suspensions are fabricated with polyelectrolyte dispersants and the rheology is tailored to a yield pseudoplastic state for proper flow through the extrusion orifice. Orifice sizes range between 200 and $2000 \mu \mathrm{m}$ and parts may be built at rates on the order of $1 \mathrm{~cm}^{3}$ per minute to dimensional tolerances within $+/ .020 "$.

\section{Robocasting Schematic}

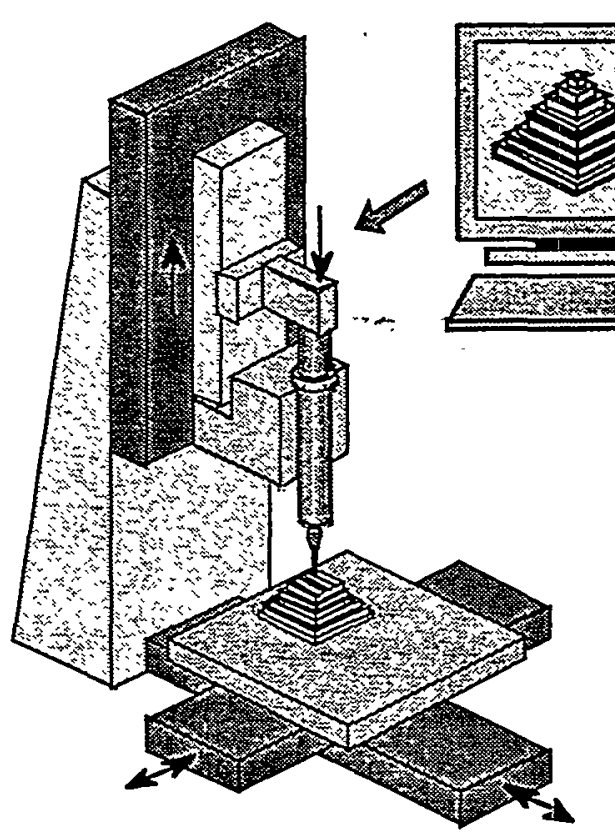

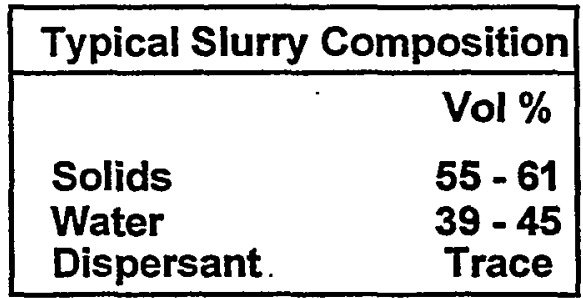

Pen tip size range: $250-1500 \mu \mathrm{m}$

- Robotically controlled extrusion of highly concentrated colloidal slurries

- Any conceivable pattern may be built layer by layer into a three dimensional shape - Dimensional control and solidification require synergy among slurry rheology, dispensing rate, and drying kinetics 
This report includes a description of the robocasting process, fabrication of particle suspensions suitable for robocasting, materials characterization for robocast parts, and developments for multimaterial composite structures.

This project has resulted in new funding in which robocasting technology is being exploited for research and development of PZT voltage bar fabrication, $\mathrm{ZnO}$ varistor fabrication, and alumina / Mo cermet fabrication for enhanced neutron generator. reliability.

\section{ACKNOWLEDGMENTS}

The authors would like to acknowledge the following individuals for their contributions to the successful completion of this project. Prof. Paul Calvert from the University of Arizona for first introducing the authors to the field of solid freeform fabrication; Lane Harwell for assistance in the design and selection of the robocasting equipment; Mark Ensz for assistance in the implementation and development of motion control software; Ray Thornton for design and drawing of mechanical fixtures for the robocasting equipment; Bruce King for fulfilling the critical role of liaison between the material science and mechanical engineering personnel; and Prof. Jennifer Lewis from the University of Illinois for providing experimental data related to measurement of drying stresses in robocasting slurries. 


\section{CONTENTS}

Title

Abstract

Summary

Acknowledgments

Introduction

The Robocasting Technique

Slurry Properties and Build Parameters

Material Properties

Multimaterial Applications

Conclusions

References

\section{FIGURES}

1 Front view and side view of slurry deposition. $\quad$ - 6

2A Schematic of viscosity versus percent solids for dispersed slurries. $\quad 7$

2B Schematic showing "solidification" during building by a pseudoplastic / dilatant transition.

3 Examples of robocast parts.

4 Flexural strength of aluminum oxide bend bars fabricated by various techniques.

5 Residual surface texture and surface roughness as a function of bead overlap during deposition.

6 Robocast aluminum oxide preforms infiltrated with metal 14 form graded interlocking composites.

$7 \quad$ Mixing head capable of depositing four slurries simultaneously. $\quad 14$

$8 \quad$ Graded transition between two slurries. 15

9 Robocasting aluminum oxide along with a fugitive material. 15

\section{TABLE}

I A current list of material systems used with robocasting. 


\section{INTRODUCTION}

Solid freeform fabrication is the near-net-shape manufacturing of components by sequentially stacking thin layers of material until complicated three-dimensional shapes are produced. The operation is computer controlled and requires no molds. This exciting new field of technology provides engineers with the ability to rapidly produce prototype parts directly from CAD drawings and oftentimes little or no machining is necessary after fabrication. Techniques for freeform fabrication with several types of plastics and metals are already quite advanced and may be reviewed in references 1 and 2 . Very complicated plastic models can be fabricated by stereolithography, selective laser sintering, fused deposition modeling, or three-dimensional ink jet printing. Metals may be freeformed by the LENSTM technique and porous ceramic bodies by three-dimensional printing into a porous powder bed. However, methods for freeform fabrication that utilize particulate slurries to build dense ceramics and composites are not as well developed.

The techniques that are being developed for the freeform fabrication of dense structural ceramics primarily revolve around the sequential layering of ceramic loaded polymers or waxes. Laminated Object Manufacturing and CAM-LEM processing use controlled stacking and laser cutting of ceramic tapes [2,3]. Similar to fused deposition modeling, ceramic loaded polymer/wax filaments are being used for the fused deposition of ceramics [2,4]. Extrusion freeform fabrication uses high-pressure extrusion to deposit layers of ceramic loaded polymer/wax systems[1]. Modified stereolithographic techniques are also being developed using ceramic loaded ultraviolet curable resin [2]. Pre-sintered parts made with any of these techniques typically have $40-55$ vol.\% polymeric binder. In this regard, these techniques are analogous to powder injection molding of ceramics. Very long and complicated burnout heat treatments are necessary to produce a dense ceramic, free of organics. Heating rates of 0.2 degrees Celsius per minute are common. [5] Thus, while a part may be rapidly prototyped within a few hours, it takes several days to densify.

In contrast, robocasting is a freeform fabrication technique that utilizes particulate slurries but does not require organic binders. Since binder burnout is not an issue, a dense ceramic part may be freeformed, dried, and sintered in less than 24 hours. In some regards, robocasting is analogous to the ceramic near-net-shape processing techniques, slip casting and gel casting [6]; however, robocasting is moldless and fabrication times can be quicker. 


\section{THE ROBOCASTING TECHNIQUE}

Robocasting uses robotics to control layerwise deposition of ceramic slurries through an orifice. Orifice openings can range from a couple of millimeters to tenths of millimeters. The process is based on the extrusion of highly loaded ceramic slurries that are typically $50-65$ vol.\% ceramic powder, $<1$ vol.\% organic additives, and $35-50$ vol.\% volatile solvent (usually water). Conceptually, robocasting is no more complicated than icing a cake or caulking a bathtub. However, during robocasting the build platform moves beneath a stationary-dispensing tip.
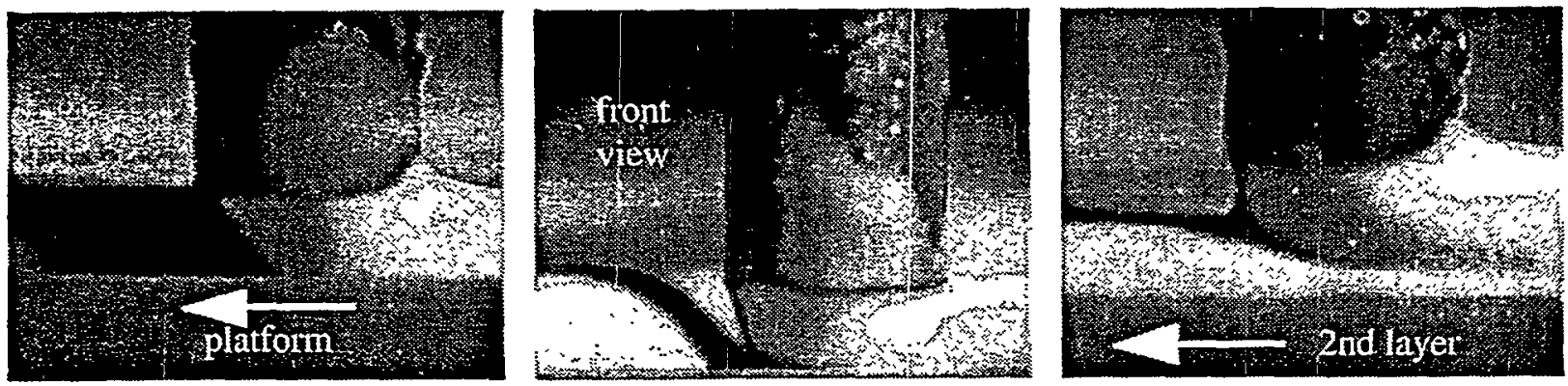

Figure 1: Slurries are deposited layer-by-layer forming three-dimensional shapes. Arrows represent motion relative to the platform. The platform is actually moving opposite to the arrows.

In general, a robocasting slurry must meet three criteria: 1) it must be pseudoplastic enough to flow through a small orifice at modest shear rates; 2) it must setup into a nonflowable mass upon dispensing; and 3) it must be able to "accept" multiple layers without defects to form a uniform mass. Probably the most unique and interesting aspect of robocasting is the process by which the flowing pseudoplastic slurry transforms into a solid-like mass after deposition. In contrast to gel casting and other freeform fabrication techniques, robocasting does not require organic polymerization reactions or solidification of a polymeric melt for the solid transformation. On the contrary, in order to maintain structural integrity while building a component, robocasting relies on the rheology of the deposited slurry and on partial drying of the individual layers. This is explained below.

Typical ceramic powder slurries have an average particle size on the order of several microns and posses a relatively monosized distribution. Ceramic powders with this character, which are dried from dispersed slurry, typically pack into a consolidated structure that is approximately $65 \%$ of the theoretical density. The character of flowable 
slurries with solids loadings just below the consolidated density is crucially important for robocasting. Figure $2 \mathrm{~A}$ depicts schematically the behavior of a typical dispersed alumina powder slurry. Dispersed slurries have very low viscosity and are rheologically Newtonian at low solids loadings. Around 40 volume percent solids, the slurries begin to show pseudoplastic shear-thinning behavior even though the viscosity is still relatively low. As the solids content approaches 60 volume percent, inter-particle interactions and inter-particle collisions become dominant, viscosity begins to increase appreciably and the rheological behavior becomes highly shear thinning. Particle mobility becomes restricted and the slurry locks up into a dilatant mass at approximately 63 volume percent solids. Therefore, it is desirable to robocast with slurries that have solids loadings approaching the dilatant transition so that with minimal drying a robocasted layer becomes structurally sound and a foundation upon which more layers may be deposited.

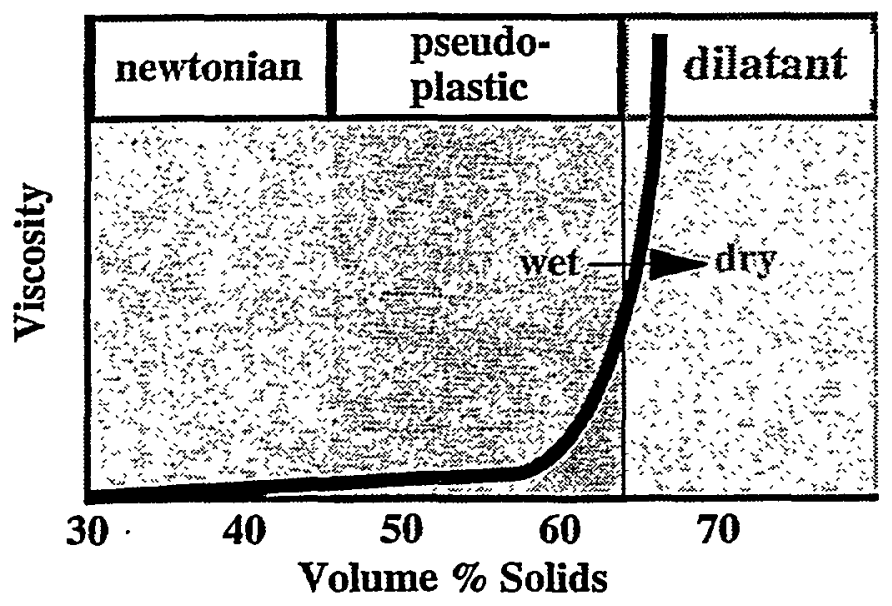

$\mathbf{A}$

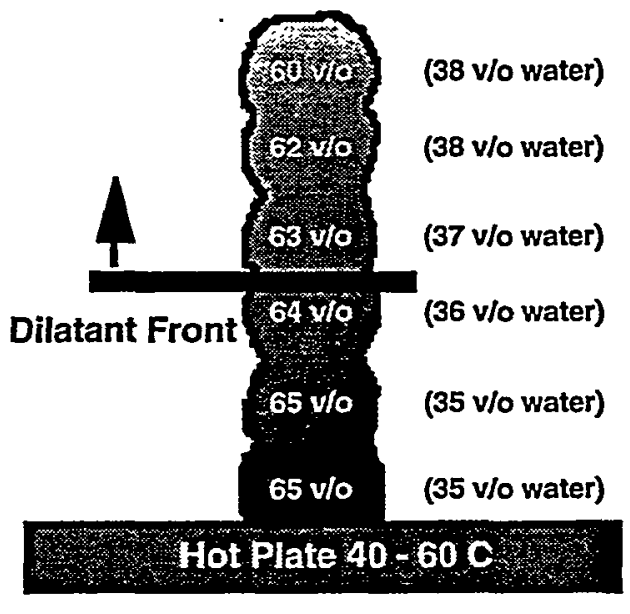

B

Figure 2: A) A schematic showing the typical viscosity versus volume percent solids behavior for dispersed aluminum oxide slurries. For optimal robocasting, work close to the dilatant transition. B) A schematic showing how a part "solidifies" during building through a pseudoplastic / dilatant rheological transition.

The schematic in Fig. 2B is a visualization tool that shows how the pseudoplastic to dilatant transition must be in sync with the build rate in order to maintain structural integrity for thick parts. Therefore, the drying kinetics of the freshly deposited beads determines the optimum build parameters. Typically, parts are built upon a platform heated between 30 and 60 degrees Celsius to assist the pseudoplastic to dilatant transition. For thick parts it may be necessary to incorporate an additional heat source 
above the build platform. Using Fig. 2B as an aid, it may be visualized that when the drying rate is too slow, the pseudoplastic to dilatant transition is delayed and accumulated weight from several layers eventually surpasses the yield stress of the pseudoplastic layers. This condition can induce slumping and the creation of nonuniform walls. Conversely, if the drying rate is too fast, warping, cracking, and delamination may occur.

In general, proper robocasting requires a synergistic control of: 1) percent solids in the ceramic powder slurry; 2) viscosity and rheology of the slurry; 3) dispensing rate of the slurry through the orifice; 4) drying kinetics of the dispensed bead of slurry; and 5) computer code for optimal machine instructions. When a proper balance of these variables is achieved, robocasting can be used to make intricate ceramic bodies that sinter into relatively strong, dense and defect-free parts.

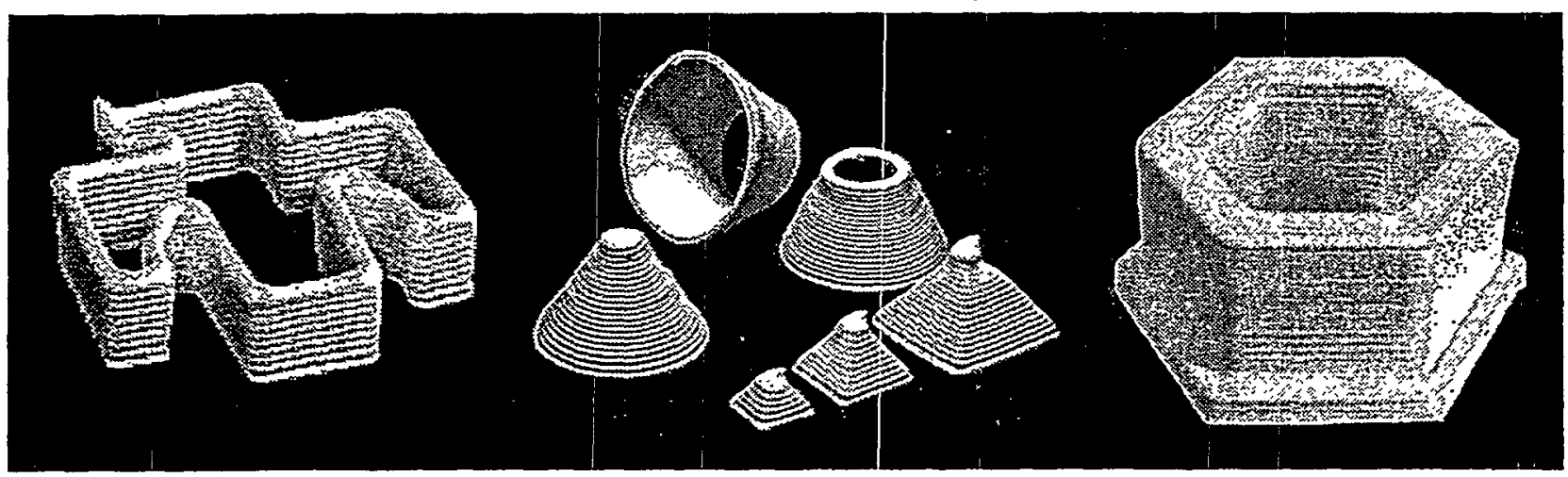

Figure 3: Examples of parts made by robocasting. Unsupported overhangs up to 30 degrees are possible.

\section{SLURRY PROPERTIES AND BUILD PARAMETERS}

As previously mentioned, slurry that is usable for robocasting must be highly concentrated and exhibit a rheology that is "yield pseudoplastic". That is, the slurry should have an appreciable yield stress when at rest but a shear-thinning behavior upon being sheared. A shear thinning slurry will have high viscosity at low shear rates but drastically lower viscosity when sheared more vigorously. Slurries with this behavior are able to flow smoothly through a small orifice and onto pre-built layers while having the ability to maintain their shape after deposition. The typical slurry properties and build conditions for robocasting slurry made with colloidal aluminum oxide is described below. 
A typical ceramic powder used is A-15 aluminum oxide from Alcoa Industrial Chemicals. The average particle size is $2.2 \mu \mathrm{m}$ with a surface area of $4.3 \mathrm{~m} / \mathrm{g}$. Deionized water is used as the solvent and Darvan 821A (R.T. Vanderbilt Corp.) as the dispersant. The aqueous alumina slurries are made according to Cesarano, et al [7] and are 58 to 61 vol.\% alumina. Darvan 821A is a salt of polyacrylic acid and can provide electrosteric repulsive forces between particles when adsorbed onto the surface of the particles. [7] Large interparticle repulsive forces are required to make slurries that contain over 50 volume percent solids but still behave like a fluid. Upon gentle mixing on a ball mill, highly concentrated slurries such as these typically exhibit a pseudoplastic rheology. However, the exact nature of the rheological behavior and resulting yield stress can be more precisely controlled by adjusting the $\mathrm{pH}$ or ionic strength of the slurry. The ionic strength and surface area of the slurry may also vary with the time of mixing. Therefore, aging may be easily utilized to tailor the rheology for optimal robocasting. Our aluminum oxide slurries are aged for up to 20 days by gently mixing on a ball mill. The viscosity of the slurry is periodically measured with a Brookfield DV-III programmable rheometer with a concentric cylinder attachment. When the slurry shows a shear thinning (pseudoplastic) behavior with an adequate yield stress at rest, it is used to build parts. Most usable slurries require a stress of $40-50 \mathrm{~Pa}$ to induce yield however only a very small increase in shear stress is required to induce more substantial flow. For example, a good building aluminum oxide slurry has a viscosity of nearly $1 \times 10^{6} \mathrm{cP}$ at a shear rate of at $0.07 \mathrm{~s}^{-1}$ and a viscosity of $40,000 \mathrm{cP}$ at $1.7 \mathrm{~s}^{-1}$. This is a very large decrease in viscosity over a small increase in shear rate. As a reference, the shear induced by sweeping a brush full of paint on to a house is on the order of $200 \mathrm{~s}^{-1}$. A typical shear rate through a robocasting orifice is approximately $20 \mathrm{~s}^{-1}$.

The build parameters used during robocasting depend upon the intricacy of the part and whether it is more important to obtain a smooth surface or build large parts quickly. However, in general, the diameter of the dispensing orifice can be as small as $200 \mu \mathrm{m}$ or as large as $2 \mathrm{~mm}$. The layer thickness of the beads of slurry that are extruded . can similarly range from approximately $200 \mu \mathrm{m}$ to $1.5 \mathrm{~mm}$. The slurry is extruded onto a platform that is usually kept at $30-50$ degrees Celsius with the surrounding relative humidity ranging from $25-50 \%$. Beads are drawn at table speeds that range between 3 and $20 \mathrm{~mm} / \mathrm{s}$. Under these conditions, the slurry is deposited at rates ranging from $15-$ $50 \mathrm{~cm}^{3} / \mathrm{h}$. Also, in order to encourage better knitting between beads and to obtain smother surface finishes, beads may be overlapped during building by up to $50 \%$. 


\section{MATERIAL PROPERTIES}

Robocast samples made from the same aluminum oxide slurries discussed above have been characterized and compared to samples made by more traditional techniques. In particular the density, mechanical strength and surface roughness have been measured. Bend bars were made from the same A-15 Alcoa aluminum oxide. Bars were fabricated by uniaxially dry pressing at $6 \mathrm{ksi}$, isostatically dry pressing at $25 \mathrm{ksi}$, slip casting 40 volume percent slurries into plaster molds, and robocasting from a $0.8 \mathrm{~mm}$ nozzle at 10 $\mathrm{mm} / \mathrm{s}$ at 40 degrees Celsius. The robocast bars were made with different build patterns to examine the effect of bead alignment (lengthwise, widthwise, and crosshatch). Another set of samples was built to examine the effect of build pattern and bead overlap on surface finish.

Archimedes density measurements were completed and revealed that there is not any significant reduction in density due to robocasting processing. Green (consolidated) densities were measured after drying and sintered densities measured after sintering at 1650 degrees Celsius for two hours. The green densities for all of the samples were 69.8 $(+/-1.5 \%)$ percent theoretical with the exception of the uniaxially pressed samples (64.5\%). The sintered densities for all of the samples were $94.1(+/-1.1)$ percent theoretical. These are reasonable values for the unmilled A-15 aluminum oxide powder used which has relatively large particle sizes and low sinterability.

The flexural strength results from four-point bend measurements are shown in Figure 4. It should be noted that since A-15 aluminum oxide is not an optimal powder for making high strength parts and the samples were only ground with a 320 grit wheel (not polished), the values shown are not as high as are often listed for high purity aluminas. However, the relative values are still useful for determining differences due to processing. As expected, the slip cast bars performed better than the isostatically pressed bars and the uniaxially pressed bars. However, the most important comparison is between robocast bars and slip cast bars. It is generally regarded that with the exception of hot pressing, fabricating ceramics with slurry processing methods and slip casting in particular, yield the highest quality parts. Robocast and slip cast bars are compared in Fig. 4 and robocasting fares well. In an effort to examine structural anisotropy robocast parts were fabricated in three different patterns and they are shown schematically in Figure 4. In the lengthwise build the bars were fractured so that the crack had to propagate across all of the beads. In the widthwise build the bars were fractured so that the crack could propagate between the beads. The crosshatch build is a mixture of the two. On a positive note, the data in Figure 4 shows that regardless of build pattern, 
robocast bars have strengths higher than the pressed samples. This fact alone indicates that robocast parts can be made relatively strong when compared to parts fabricated more traditionally. However, it is also interesting to note that robocast bars built lengthwise show comparable strengths to slip cast bars while widthwise and crosshatch bars show a $20 \%$ reduction in strength. Therefore, it may be inferred that even though the overall strength of robocast parts built in any orientation are relatively free of gross defects related to processing, there is indeed some degree of anisotropy induced by robocasting. Also, the anisotropy causes the strength between neighboring beads to be less than the bulk strength within the beads. Since it is desirable to control or perhaps eliminate all anisotropy, the cause of this anisotropy is the focus of on going research. It is speculated that the cause of the anisotropy is due to density gradients formed by drying stresses or particle orientation that occurs during the extrusion process.

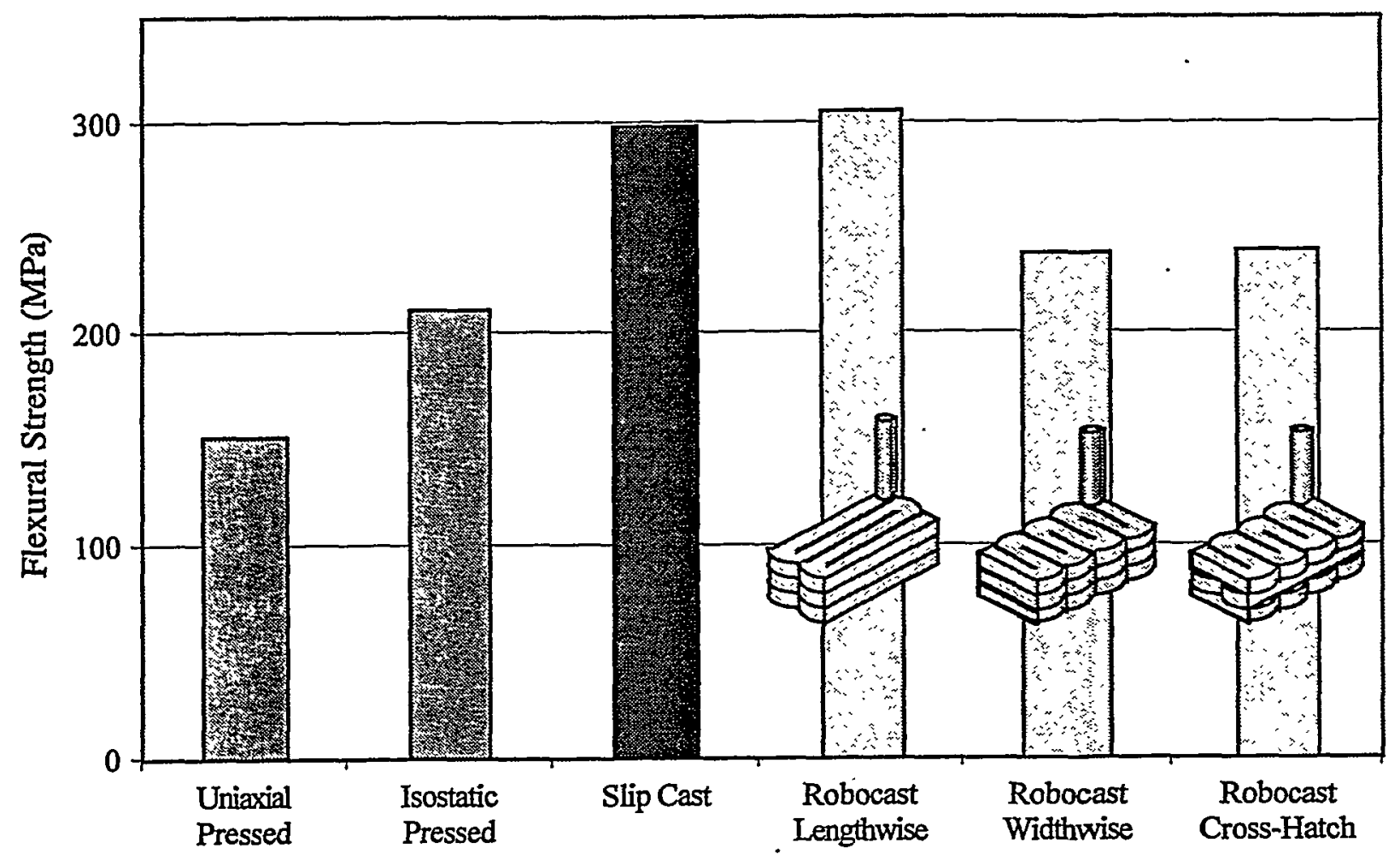

Figure 4: The flexural strength of sintered aluminum oxide bend bars for various fabrication techniques. Robocast samples were built using three different deposition patterns. 
Another important parameter for judging the usefulness of robocasting and ultimate part quality is the measure of surface roughness. Since parts are built from the layering of beads there will always be a degree of surface roughness on the external surfaces. For many applications the surface roughness may not be a problem but for most applications it will be desirable to eliminate or at least minimize the amount of machining necessary to meet final tolerances. For this reason, studies are being completed to understand how surface roughness may be reduced during robocasting processing. As a start, samples were built to examine the effect of build pattern and bead overlap on surface finish. It was determined that crosshatch build patterns can help make part fabrication less sensitive to defects that occur during the deposition process when compared to lengthwise build patterns. In lengthwise builds, deposition over defects is more conformal and defects present in one layer may still be present or perhaps exasperated ten layers later. Crosshatch building seems to smear out defects over several layers. The result is that crosshatch builds can yield parts with a smoother surface finish. However, it should be noted that this effect is secondary in nature and a far greater effect on surface roughness is observed by varying the amount of bead overlap during building. Bead overlap is the relative distance that the platforrn table translates when drawing two beads side-by-side. If after drawing one bead the table translates a distance that is exactly the diameter of the dispensing orifice then overlap equals zero. That is, the center-to center distance between beads is equal to the orifice diameter. If the platform only translates the radius of the orifice then the center-to-center distance between beads is equal to $50 \%$ of the orifice diameter and the bead overlap is defined as $50 \%$. Therefore, \% Overlap $=100(\mathrm{D}-\mathrm{C}) / \mathrm{D}$ where $\mathrm{D}$ is the diameter of the orifice and $\mathrm{C}$ is the center-tocenter distance between neighboring beads within the same layer. It is thought that positive bead overlap may help neighboring beads of slurry knit together more homogeneously. However, bead overlap may be positive or negative. Robocasting with positive overlapping requires that the dispensing rate be correspondingly decreased to prevent the formation of excess slurry around the dispensing tip. Conversely, robocasting with negative overlapping means that the center to center distance between neighboring beads is greater than the diameter of the orifice. Therefore, the slurry deposition rate must be correspondingly increased so that there is enough slurry available to completely fill in the volume between beads. With negative overlapping, slurry is being pushed together to meld neighboring beads where as with positive overlapping the slurry is being pulled over the previously deposited bead and the beads are being smeared together. The results of this study are depicted in Figure 5 and show that overlap can indeed have a tremendous effect on surface roughness. The data in Figure 5 was collected with a laser profilometer for samples made with a rather large orifice of $1.27 \mathrm{~mm}$. For negative overlap between -30 to $-60 \%$ the peak to valley roughness is approximately 150 to 200 $\mu \mathrm{m}$ while the RMS roughness is about $2000 \mu \mathrm{inch} / \mathrm{inch}$. In contrast, overlap of $+40 \%$ 
yields peak to valley roughness of less than $50 \mu \mathrm{m}$ and RMS roughness less than 200 $\mu$ inch/inch. For comparison, 80 grit sandpaper has an RMS roughness of approximately 1000 and slip cast ceramic bodies on the order of 100. In conclusion, if surface texture is a concern for a given part then positive overlapping can yield impressive results even for relatively large dispensing tips. If surface finish is not a concern, large parts may be built very quickly by utilizing negative overlapping.
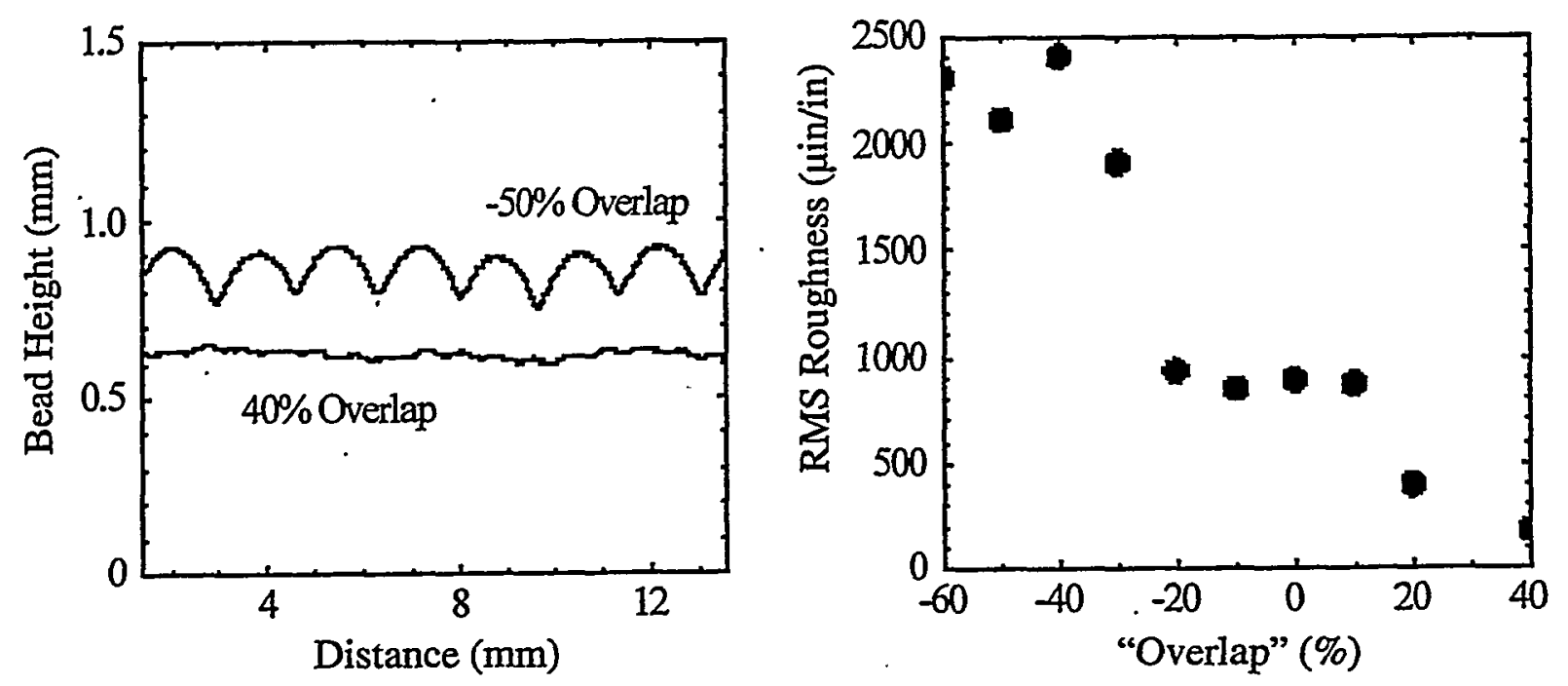

Figure 5: Non-contact laser profilometry data shows residual surface texture and surface roughness as a function of the amount of bead overlap that was used during the deposition process.

\section{MULTIMATERIAL APPLICATIONS}

In addition to fabricating single material parts, robocasting may have utility for the manufacture of intricate preforms for the fabrication of ceramic / metal joining composites. By robocasting various crosshatch patterns, intricate structures may be fabricated that can not obviously be manufactured by traditional fabrication techniques. Figure 6A shows a cross-section of a robocast aluminum oxide part fabricated with regions of closed porosity as well as open voids with large undercuts. This type of structure when infiltrated with a metal forms a mechanically bonded ceramic to metal join that has a graded composition on a macroscale. Figure $6 \mathrm{~B}$ shows the cross-section of a similar preform that was infiltrated with an active metal (TiCuSil). This part not only showed exemplary bonding without cracking but also was subsequently used, as a platform upon which LENS $^{\text {TM }}$ [2] processed stainless steel was freeformed. In finality, a structurally sound crack-free part was fabricated that transitioned from $100 \%$ alumina to 
$100 \%$ stainless steel. Additionally, the part was mostly freeformed. The TiCuSil metal used to fabricate the composite in Fig. $6 \mathrm{~B}$ is probably prohibitively expensive for any widespread application. Therefore, a method for infiltrating aluminum metal into a robocast alumina preform was developed. Figure $6 \mathrm{C}$ shows a cross-section of a structurally sound alumina / aluminum part that is macroscopically graded with some mechanical interlocking.
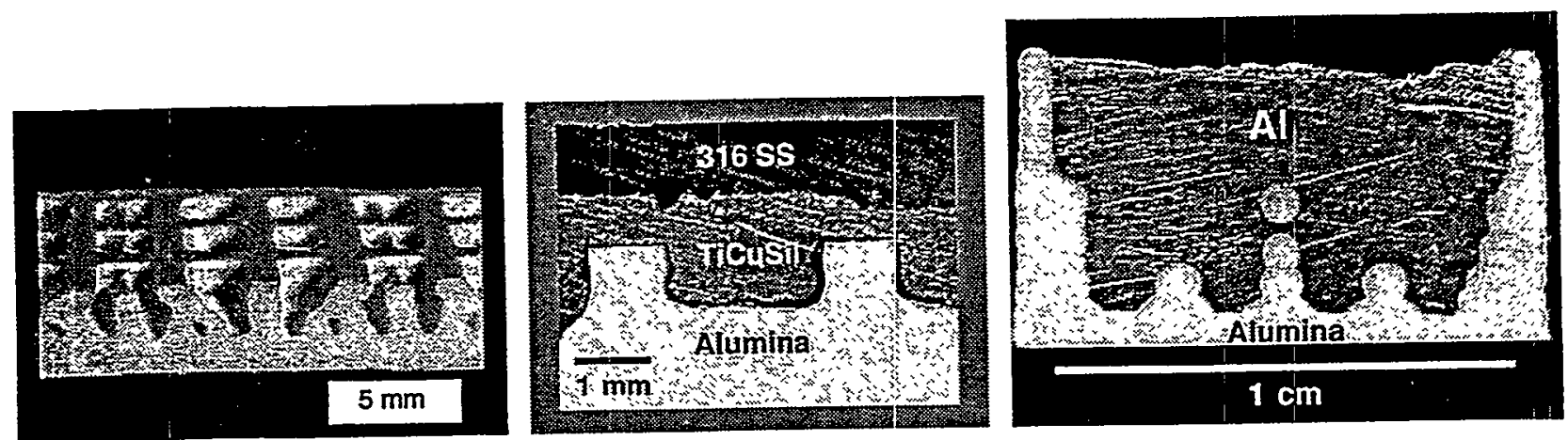

Figure 6: Robocast aluminum oxide preforms infiltrated with metal form graded interlocking composites.

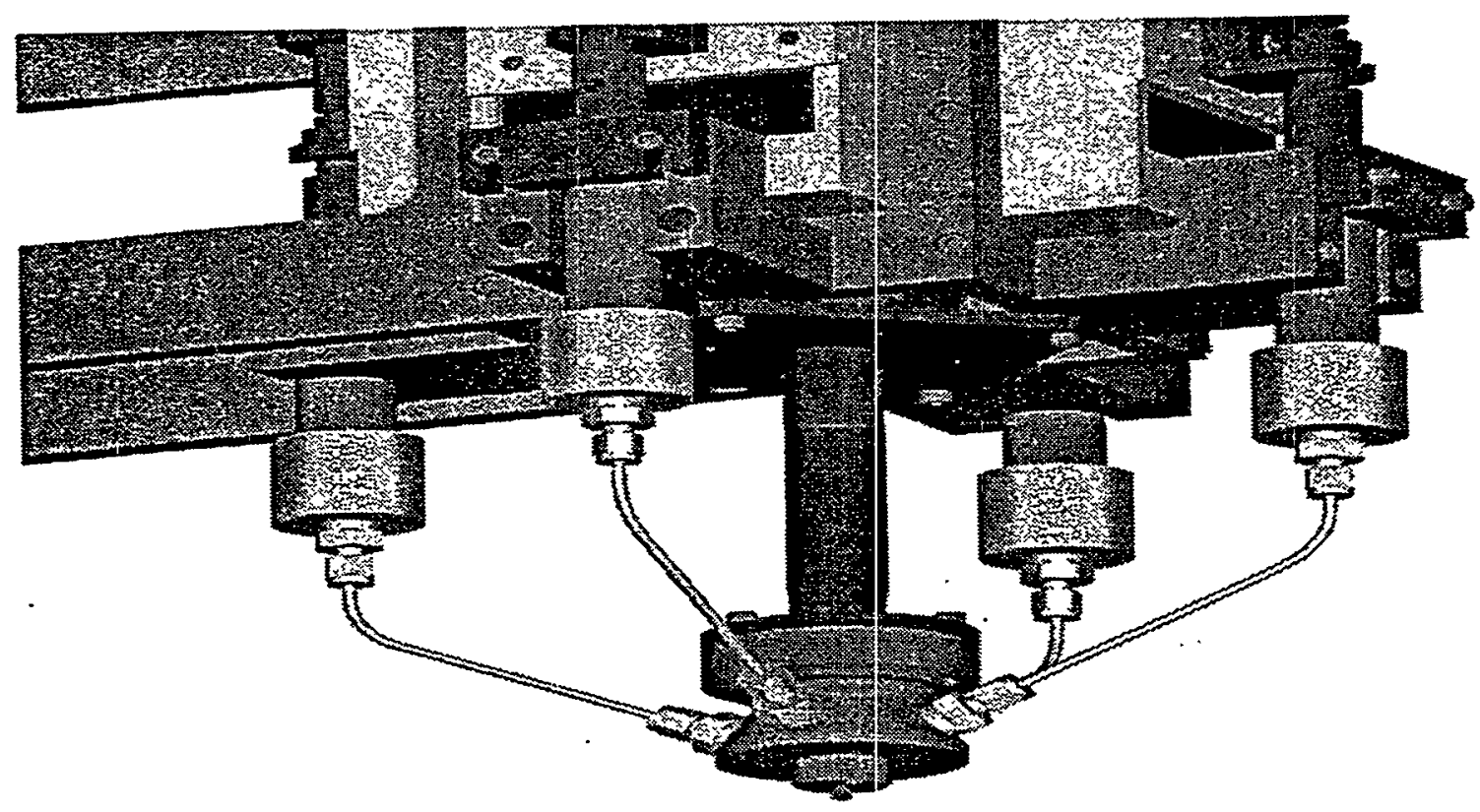

Figure 7 Mixing head capable of depositing four slurries simultaneously. 
The ability to deposit more than one material through a single orifice is a recent advance for robocasting that should increase its versatility. Figure 7 shows a schematic of a mixing head that has the capability to dispense up to four different materials. Just before the orifice there is a miniature mixing chamber with a $3 \mathrm{~mm}$ rotating paddle. When it is desired to deposit ratios of various materials the mixer can be turned on to ensure that a uniform mixture is dispensed through the orifice. For separate and discrete placement of materials, the mixer is turned off.

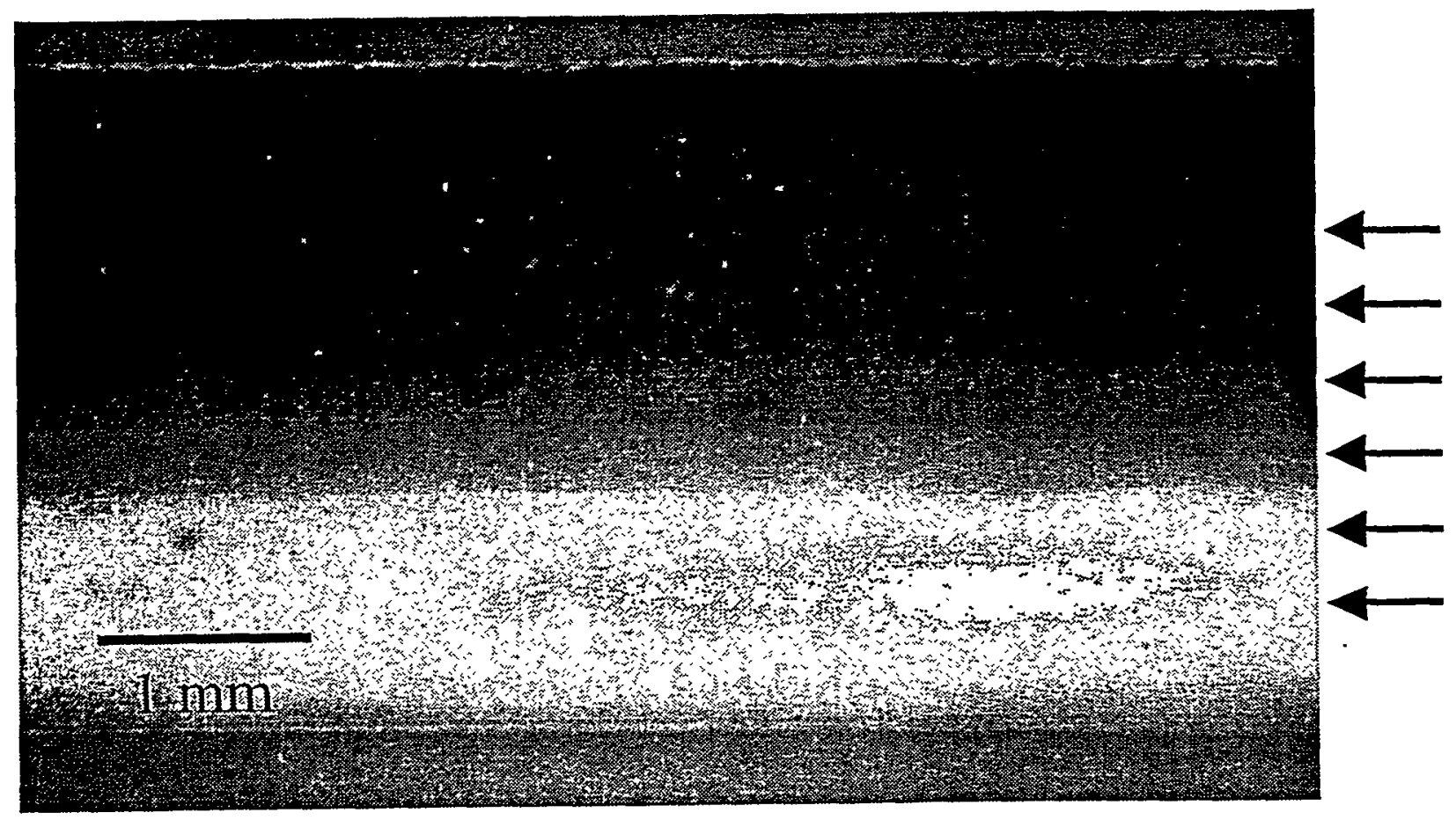

Figure 8: Demonstration of a graded transition between two slurries over six layers.
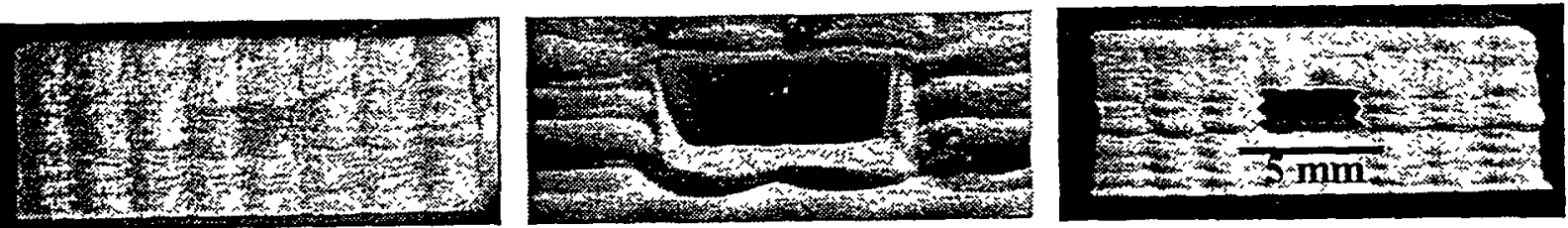

Figure 9: Robocasting aluminum oxide along with a fugitive material to demonstrate how truly three-dimensional parts may be freeformed. Both slurries were deposited with a dual feed mixer through a single orifice. 
Figure 8 shows a visual example of complete grading between two materials. This experiment was completed on a dual feed mixing head with a bead height of approximately $300 \mu \mathrm{m}$ and shows a gradual 100 percent transition from one material to the other over six layers. Additionally, in order to build truly three-dimensional parts with overhangs, hidden features, and/or buried materials, robocasting must also have the capability to deposit multimaterials discretely. This capability is demonstrated in Fig. 9 for a part fabricated with a horizontal channel that is four bead widths wide. The part in Fig. 9 is made with an aluminum oxide slurry and a fugitive support material. During the build the fugitive material supports the top two layers of aluminum oxide. During drying the fugitive material deforms and is pulled into a thin layer by the surrounding aluminum oxide matrix. During binder burnout and sintering the fugitive material decomposes prior to aluminum oxide densification. In conclusion, it was determined that for a fabrication technique such as robocasting (i.e., one in which liquid wicking and drying are part of the solidification process) an ideal fugitive material must have the following properties: 1) very low solids and organic contents; 2 ) a high enough yield strength to be an adequate supporting platform; and, 3) a low enough yield stress to deform during wicking and drying without disrupting neighboring materials.

The focus of future work is on the moldless manufacture of intricately shaped composites and hybrid electronic packages. This task requires a significant effort in the development of computer software that can analyze a CAD file and convert the file into a set of machine instructions that optimize pröcessing parameters producing high quality robocast components with precise control of feature resolution. Additionally, there is an effort to incorporate smart processing capabilities into robocasting with the aid of sensors and computer modeling. Sensors that monitor build conditions in real time are being incorporated into the system to provide closed loop sensor-based feedback. Computer simulations of the relevant physical phenomena; flow during dispenșing, bead shape development, prediction of the pseudoplastic / dilatant transition, and dimensional changes during drying are also being developed for knowledge-based processing control. These simulations will be used in combination with real time sensor feedback to interpret and calculate optimal adjustments of processing parameters during component fabrication.

Finally, Table $I$ is included to show the current list of materials systems that have been made into robocasting slurries and fabricated into parts. 


\section{Table I}

A Current list of materials systems used with robocasting.

$\begin{array}{ll}\text { Alumina (dense and porous) } & \mathrm{PZT} \text { (aqueous and non-aqueous) } \\ \mathrm{Al}_{2} \mathrm{O}_{3} \text { / TiCuSil composites } & \mathrm{PMN} \\ \mathrm{Al}_{2} \mathrm{O}_{3} \text { / } \mathrm{Al} \text { composites } & \mathrm{ZnO} \\ \mathrm{Al}_{2} \mathrm{O}_{3} \text { / Mo } & \\ \text { Kaolin } & \text { Thick film pastes } \\ \text { Stabilized Zirconia } & \text { Polymers } \\ \text { Mullite } & \text { Epoxy } \\ \text { Silicon Nitride } & \text { Solder }\end{array}$

\section{CONCLUSIONS}

A new freeform fabrication technique has been developed for the manufacture of ceramics called robocasting. Highly concentrated fine particle slurries are robotically extruded layer-by-layer into complicated three-dimensional structures. The process is completely moldless and depending on the required component tolerance, final machining may not be necessary. Parts may be fabricated at a rate of approximately 1 $\mathrm{cm}^{3}$ per minute to dimensional tolerances within $+/-.020$ ". Components may be built, dried, and sintered to near theoretical density within 24 hours. Robocasting lends itself to rapid prototyping or manufacturing. In fact, robocasting provides an avenue to manufacture components with unique structures on a macroscopic scale that can not be easily fabricated with traditional techniques. Robocast components have mechanical properties that are comparable to parts made with more traditional fabrication techniques. Robocasting also has the capability of creating multimaterial components that have graded compositions for tailored property response or discrete material placement for hybrid components with tailored functionality. In any event, the robocasting fabrication process developed in this LDRD project, "Freeforming of Ceramics and Composites From Colloidal Slurries", has far reaching potential for advanced manufacturing. of ceramics components for the defense sector and for commercial applications. 


\section{REFERENCES}

1. P. Calvert and R. Crockett, Chem. Mater., 9, 650-63 (1997).

2. Proceedings of the Solid Freeform Fabrication Symposium, Vol. 1990, 1991, 1992, 1993, 1994, 1995, 1996, 1997, 1998. Edited by D. L. Bourell, J. J. Beaman, R. H. Crawford, H. L. Marcus, and J. W. Barlow, The University of Texas at Austin, Austin Texas.

3. E. A. Griffin, D. R. Mumm, and D. B. Marshall, The American Ceramic Society Bulletin, Vol. 75, No. 7, 65-68, July 1996.

4. M. K. Agarwala, et al, The American Ceramic Society Bulletin, Vol. 75, No. 11, 60-65, November 1996.

5. Remco Van Weeren, AlliedSignal Research and Technology, Morristown NJ, personal communication.

6. A. C. Young, O. O. Omatete, M. A. Janney, and P. A. Menchhofer, J. Am. Ceram. Soc., 74, 3, 612-18 (1991).

7. J. Cesarano III and I. A. Aksay, J. Amer. Ceram. Soc., 71, 12, 1062-67 (1988). 


\section{DISTRIBUTION:}

$\begin{array}{lll}1 & \text { MS-0188 } & \text { D. L. Chavez, LDRD Office } \\ 1 & \text { MS-0516 } & \text { J. P. Brainard } \\ 1 & \text { MS-0826 } & \text { T. A. Baer } \\ 3 & \text { MS-0958 } & \text { M. L. Griffith } \\ 10 & \text { MS-1349 } & \text { J. Cesarano } \\ 1 & \text { MS-1349 } & \text { H. B. Denham } \\ 1 & \text { MS-1349 } & \text { J. N. Stuecker } \\ 1 & \text { MS-1405 } & \text { B. A. Tuttle } \\ 1 & \text { MS-1411 } & \text { J. A. Voigt } \\ 1 & \text { MS-9018 } & \text { Central Technical Files, 8940-2 } \\ 2 & \text { MS-0899 } & \text { Technical Library, 4916 } \\ 1 & \text { MS-0612 } & \text { Review \& Approval Desk, 4912 } \\ & & \text { For DOE/OSTI } \\ 1 & \text { MS-0161 } & \text { Patent and Licensing Office, 11500 }\end{array}$

